\title{
Evaluation of Inhaled Procaterol for Potential Assist Use in Patients with Stable Chronic Obstructive Pulmonary Disease
}

\author{
Norio Kodaka Toru Yamagishi Kayo Watanabe Kumiko Kishimoto \\ Chihiro Nakano Takeshi Oshio Kumiko Niitsuma
}

Nagashige Shimada Hiroto Matsuse

Division of Respiratory Medicine, Department of Internal Medicine, Toho University Ohashi Medical Center, Tokyo, Japan

\section{Significance of the Study}

- The usefulness of short-acting bronchodilator assist use for stable COPD remains uncertain. The present study showed that the use of procaterol, a short acting $\beta_{2}$-agonist, improved the pulmonary function measured by spirometry and respiratory mechanics in patients with stable COPD treated with long-acting bronchodilators. Thus, inhaled procaterol has the potential for assist use for COPD. Additionally, FOT could be a useful non-invasive method for evaluating the respiratory system in COPD patients unable to perform spirometry.

\section{Keywords}

Chronic obstructive pulmonary disease - Assist use .

Forced oscillation technique - Procaterol .

Respiratory resistance

\begin{abstract}
Objectives: International guidelines recommend the use of long-acting bronchodilators for the treatment of chronic obstructive pulmonary disease (COPD), but the usefulness of short-acting bronchodilator assist use for stable COPD remains uncertain. The purpose of the present study was to objectively demonstrate the effects of assist use of procaterol, a short-acting $\beta_{2}$-agonist, on the respiratory mechanics of stable COPD patients treated with a long-acting
\end{abstract}

bronchodilator using forced oscillation technique (FOT) and conventional spirometry. We also confirmed the length of time for which procaterol assist could significantly improve the pulmonary function. Methods: We enrolled 28 outpatients with mild to severe COPD (Global Initiative for Obstructive Lung Disease stages I-III), who had used the same long-acting bronchodilator for longer than 3 months and who were in stable condition. All measures were performed using both FOT and spirometry sequentially from $15 \mathrm{~min}$ to $2 \mathrm{~h}$ after inhalation. Results: Compared to baseline, inhaled procaterol assist use modestly but significantly improved spirometric and FOT measurements within $2 \mathrm{~h}$ after inhalation. These significant effects continued for at least $2 \mathrm{~h}$. Significant correlations were found between parameters measured by spirometry and those measured by FOT.

\begin{tabular}{ll}
\hline KARGER & $\begin{array}{l}\text { Ko 2018 The Author(s) } \\
\text { Published by S. Karger AG, Basel }\end{array}$ \\
$\begin{array}{l}\text { Openger } \\
\text { E-Mail karger@karger.coms }\end{array}$ \\
www.karger.com/mpp & $\begin{array}{l}\text { This is an Open Access article licensed under the Creative Commons } \\
\text { Attribution-NonCommercial-4.0 International License (CC BY-NC) } \\
\text { (http://www.karger.com/Services/OpenAccessLicense), applicable to } \\
\text { the online version of the article only. Usage and distribution for } \\
\text { commercial purposes requires written permission. }\end{array}$
\end{tabular}

Hiroto Matsuse, $\mathrm{MD}, \mathrm{PhD}$

Division of Respiratory Medicine, Department of Internal Medicine Toho University Ohashi Medical Center

2-17-6 Ohashi, Meguro-ku, Tokyo 153-8515 (Japan)

E-Mail hiroto.matsuse@med.toho-u.ac.jp 
Conclusions: Procaterol assist use modestly but significantly improved pulmonary function determined by spirometry and respiratory mechanics in patients with stable COPD treated with long-acting bronchodilators. Thus, inhaled procaterol has the potential for assist use for COPD.

(c) 2018 The Author(s)

Published by S. Karger AG, Basel

\section{Introduction}

International guidelines recommend the use of bronchodilators for the treatment of chronic obstructive pulmonary disease (COPD) [1]. Among bronchodilators, short-acting $\beta_{2}$-agonists (SABAs) are used as a rescue medication for acute dyspnea. They are also used as an assist medication prior to expected exertional dyspnea, such as before pulmonary rehabilitation, in patients with COPD. In fact, SABA assist use contributes to improved activities of daily living (ADL) and quality of life of COPD patients with limited physical activity [2]. Clinical evaluations of the usefulness of SABA assist use for COPD include a questionnaire, the 6-minute walk test, and spirometry. Spirometry is also essential for the diagnosis of COPD, but it cannot be performed in patients sometimes with COPD who have significantly decreased pulmonary function and comorbidities such as severe cardiovascular diseases [3]. Thus, less invasive and objective methods are required. The forced oscillation technique (FOT) measures respiratory resistance and reactance. FOT can determine frequency-dependent respiratory resistance, which is characteristic of COPD $[4,5]$. FOT is also well correlated with clinical responses to therapeutic interventions in asthma [6]. FOT is conducted in the sitting position using a nose-clip and mouthpiece with respiration at resting levels. FOT measurements are taken during resting respiration and require very little time (less than $1 \mathrm{~min}$ ), and some reports have confirmed its reproducibility $[6,7]$. FOT can also measure other respiratory parameters determined by spirometry [8]. In the present study, an FOT machine (MostGraph ${ }^{\circledR}$ Chest Co., Ltd., Tokyo, Japan) that can measure respiratory mechanics using FOT was used [9-11].

The purpose of the present study was to objectively demonstrate the effects of SABA assist use on the respiratory mechanics of stable COPD treated with long-acting bronchodilators using FOT and conventional spirometry. The length of time that SABA assist use could significantly improve pulmonary function was also confirmed by sequentially measuring results from $15 \mathrm{~min}$ to $2 \mathrm{~h}$ after inhalation.

Procaterol Assist Use in Patients with Stable COPD

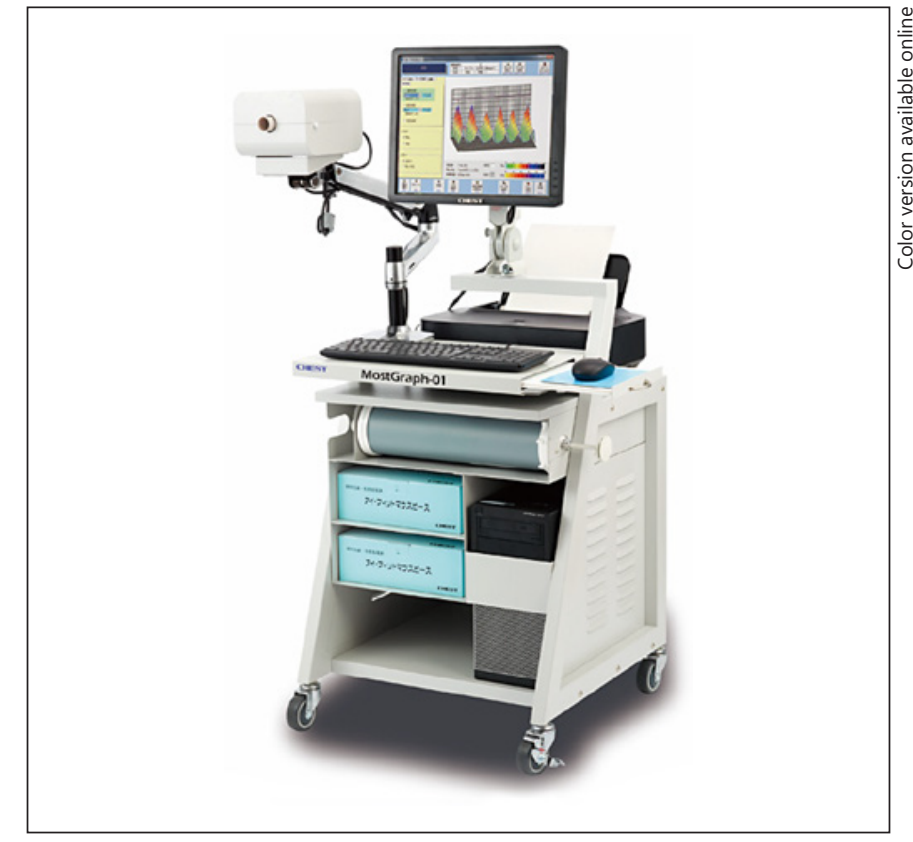

Fig. 1. Forced oscillation technique (FOT) machine $\left(\right.$ MostGraph $^{\circledR}$ Chest Co., Ltd., Tokyo, Japan).

\section{Subjects and Methods}

Between April 2012 and March 2014, a total of 168 patients with COPD, as defined by the Global Initiative for Obstructive Lung Disease [1], visited the Toho University Ohashi Medical Center. Of them, 28 were eligible and enrolled into the study based on the following inclusion criteria: they had airflow limitation classified as Global Initiative for Obstructive Lung Disease stage I-III (forced expiratory volume in $1 \mathrm{~s}\left[\mathrm{FEV}_{1.0}\right] 30-80 \%$ of the predicted value); they were using the same long-acting bronchodilator for longer than 3 months; they were in a stable condition of physical and mental health defined by COPD Assessment Test $<10$; and they had never used SABAs. All subjects had a history of smoking. Subjects were excluded from the study if they met the following exclusion criteria: 2 or more courses of oral corticosteroid or antibiotics in the previous 6 months; admission to hospital because of exacerbation in the previous 6 months; presence of large bullae or pneumothorax; severe chronic heart failure; heart rate $>100$ bpm; or use of long-term oxygen therapy. Patients who had symptoms that were compatible with bronchial asthma or a history of asthma or atopic dermatitis or peripheral blood IgE $>170 \mathrm{IU} / \mathrm{mL}$ were also excluded.

\section{Study Design}

All measures were performed with patients on their usual daily medication. After confirming an $\mathrm{SpO}_{2}>90 \%$ on room air, the absence of chest wheezing, and a heart rate $<100 \mathrm{bpm}$, both FOT and spirometry (SPIROSIFT SP-310 ${ }^{\circledR}$, Fukuda Denshi Co., Ltd., Tokyo, Japan) were performed in the afternoon. Resistances at $5 \mathrm{~Hz}$ (R5) and $20 \mathrm{~Hz}$ (R20), R5-R20, reactance at $5 \mathrm{~Hz}$ (X5), and the resonant frequency (Fres) were measured by FOT using the respiratory resistance measuring device Mostgraph-01 (MostGraph ${ }^{\circledR}$ Chest Co., Ltd., Tokyo, Japan; Fig. 1). Testing was conducted with

Med Princ Pract 2018;27:350-355 


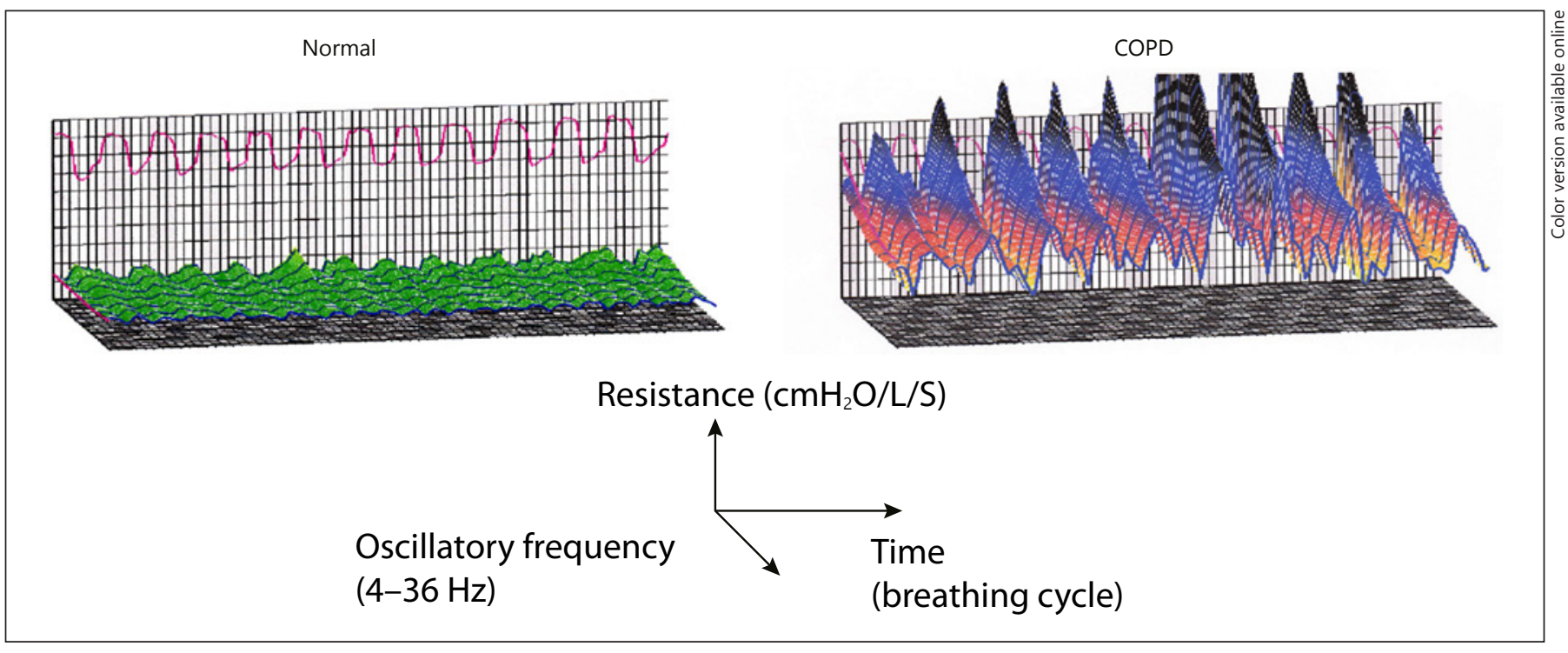

Fig. 2. Results of normal subjects and chronic obstructive pulmonary disease (COPD) patients.

the patient in the sitting position using a nose-clip and mouthpiece with respiration at resting levels. Since the measurement must be conducted at resting levels of respiration, it was conducted before tests such as spirometry that require forced respiration. For each parameter, the difference between the inspiratory and expiratory phases and the rate of change were measured. R5 and R20 reflect total and central airway resistance. Previously, R5-R20 had been thought to reflect peripheral airway resistance [12]. Recently, the anatomical relationship could not be clearly established to consider R5-R20 as an indicator of peripheral resistance, and R5-R20 is currently thought to be a parameter of ventilation inequality [4]. $\mathrm{X} 5$ presumably reflects respiratory compliance, and Fres is the point at which reactance is zero. Representative FOT results are shown in Figure 2. With spirometry, data were obtained for forced vital capacity, $\mathrm{FEV}_{1.0}$, maximum expiratory flow rate at 50\% (V50), and maximum expiratory flow rate at $25 \%$ (V25). Afterwards, subjects inhaled $10 \mu \mathrm{g}$ of procaterol hydrochloride (Meptin Air ${ }^{\circledR}$, Otsuka Pharmaceutical Co., Ltd., Tokyo, Japan) twice via metered dose inhaler as part of routine clinical care. FOT and spirometry were repeated at $15 \mathrm{~min}, 1$ and $2 \mathrm{~h}$ after inhalation. Heart rate, $\mathrm{SpO}_{2}$, and symptoms were also similarly determined.

This study received ethical approval from the Special Committee of Toho University Ohashi Medical Center (project registration number 14-80), and each patient provided written, informed consent to participate.

\section{Statistical Analysis}

Patients' characteristics are presented as means \pm SD. Numerical data are expressed as numbers (\%). Other data are expressed as medians and interquartile range (25th-75th percentile). The differences between physiological data were analyzed using the Wilcoxon rank-sum test and the Kruskal-Wallis test, as appropriate. Correlations were analyzed using Spearman's rank correlation test. All analyses were performed using SPSS Statistical software version 22.0 (Japan IBM, Tokyo, Japan). $p$ values of $<0.05$ were considered significant.
Table 1. Patients' characteristics $(n=28)$

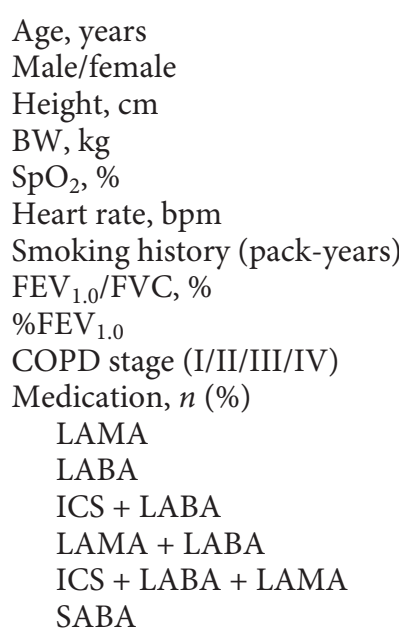

Data are presented as mean $\pm \mathrm{SD}$ or $n(\%)$.

$\mathrm{FEV}_{1.0}$, forced expiratory volume in $1 \mathrm{~s} ; \mathrm{FVC}$, forced vital capacity; LAMA, long acting muscarinic agonist; LABA, long acting $\beta_{2}$ agonist; ICS, inhaled corticosteroid; SABA, short-acting $\beta_{2^{-}}$ agonists.

\section{Results}

The characteristics of the 28 patients are shown in Table 1. Following procaterol assist use, one patient developed finger tremor, and another developed palpitations. Heart rate and $\mathrm{SpO}_{2}$ did not change significantly at any 
Table 2. Parameters of FOT and spirometry at each time point (15 min, 1 and $2 \mathrm{~h}$ ) after inhalation

\begin{tabular}{lcccc}
\hline & Before & After 15 min & 1 h later & 2 h later \\
\hline $\mathrm{R} 5, \mathrm{kPa} / \mathrm{L} / \mathrm{s}$ & $2.77(2.04$ to 3.13$)$ & $2.29(1.85 \text { to } 3.07)^{*}$ & $2.44(1.88 \text { to } 3.12)^{*}$ & $2.63(1.88 \text { to } 3.01)^{*}$ \\
$\mathrm{R} 20, \mathrm{kPa} / \mathrm{L} / \mathrm{s}$ & $2.25(1.90$ to 3.02$)$ & $2.08(1.77 \text { to } 2.59)^{*}$ & $2.11(1.73 \text { to } 2.66)^{*}$ & $2.08(1.88 \text { to } 2.58)^{*}$ \\
$\mathrm{R} 5 \bigotimes \mathrm{R} 20, \mathrm{kPa} / \mathrm{L} / \mathrm{s}$ & $0.68(0.16$ to 0.89$)$ & $0.48(0.10$ to 0.79$)$ & $0.58(0.11$ to 0.90$)$ & $0.59(0.05$ to 0.87$)$ \\
$\mathrm{Fres}, \mathrm{kPa} / \mathrm{L} / \mathrm{s}$ & $10.74(8.66$ to 12.82$)$ & $10.40(7.13 \text { to } 12.95)^{*}$ & $10.23(7.90 \text { to } 12.32)^{*}$ & $10.33(8.28 \text { to } 12.20)^{*}$ \\
$\mathrm{ALX}, \mathrm{kPa} / \mathrm{L} / \mathrm{s}$ & $3.94(2.17$ to 7.18$)$ & $3.70(0.93$ to 6.10$)$ & $3.18(1.03 \text { to } 5.41)^{*}$ & $3.78(1.50 \text { to } 6.59)^{*}$ \\
$\mathrm{X} 5, \mathrm{kPa} / \mathrm{L} / \mathrm{s}$ & $-0.91(-1.23$ to -0.54$)$ & $-0.79(-1.24$ to -0.29$)$ & $-0.69(-1.08 \text { to }-0.31)^{*}$ & $-0.84(-1.28$ to -0.54$)$ \\
$\mathrm{FEV}, 1.0, \mathrm{~L} / \mathrm{s}$ & $1.47(1.21$ to 2.02$)$ & $1.66(1.34 \text { to } 2.12)^{*}$ & $1.60(1.30 \text { to } 2.12)^{*}$ & $1.69(1.27 \text { to } 2.17)^{*}$ \\
$\mathrm{FVC}, \mathrm{L} / \mathrm{s}$ & $2.78(2.28$ to 3.10$)$ & $2.75(2.38$ to 3.23$)$ & $2.77(2.42$ to 3.23$)$ & $2.79(2.38$ to 3.21$)$ \\
$\mathrm{V} 50, \mathrm{~L} / \mathrm{s}$ & $0.94(0.52$ to 1.50$)$ & $1.11(0.68 \text { to } 1.47)^{*}$ & $1.05(0.62 \text { to } 1.46)^{*}$ & $1.07(0.59 \text { to } 1.62)^{*}$ \\
$\mathrm{~V} 25, \mathrm{~L} / \mathrm{s}$ & $0.32(0.26$ to 0.44$)$ & $0.39(0.30 \text { to } 0.53)^{*}$ & $0.35(0.27 \text { to } 0.51)^{*}$ & $0.39(0.28 \text { to } 0.54)^{*}$ \\
\hline
\end{tabular}

Data are expressed as median (interquartile range 25 th-75th percentile).

$* p<0.05$, significant difference with before inhalation.

$\mathrm{R} 5$, resistance at $5 \mathrm{~Hz} ; \mathrm{R} 20$, resistance at $20 \mathrm{~Hz}$; R5-R20, resistance at 5-20 Hz; Fres, frequency of resonance; ALX, low- frequency reactance area; X5, reactance at $5 \mathrm{~Hz}$; V50, maximum expiratory flow rate at 50\%; V25, maximum expiratory flow rate at $25 \%$.

time point after procaterol assist use. Compared to those before inhalation, R5 and R20 as parameters of respiratory resistance and Fres as a parameter of respiratory reactance improved modestly but significantly at each time after inhalation (Table 2). There were no significant differences between each time ( $15 \mathrm{~min}, 1$ and $2 \mathrm{~h}$ ) after inhalation in all parameters. R5-R20 as a ventilation inequality decreased slightly, but not significantly, following inhalation. Low-frequency reactance area (ALX) and reactance at $5 \mathrm{~Hz}(\mathrm{X} 5)$ as parameters of respiratory reactance improved slightly, but not significantly, following inhalation. $\mathrm{FEV}_{1.0}$, V50, and V25 determined by spirometry also improved modestly but significantly following inhalation in comparison with measurements before inhalation (Table 2). In terms of the correlation between FOT and spirometry, rates of changes in $\mathrm{FEV}_{1.0}$ at $15 \mathrm{~min}$ and $1 \mathrm{~h}$ after procaterol use correlated significantly with those in R5 and R20 (Table 3).

\section{Discussion}

The major findings of the present study are as follows: (1) SABA assist use modestly but significantly improved pulmonary function, even for clinically stable COPD patients already treated with a long-acting bronchodilator; (2) FOT could identify the modest but significant improvement in pulmonary function following SABA assist use; and (3) a significant correlation occurred between FOT and spirometry, though these techniques could determine different physiological parameters.

Procaterol Assist Use in Patients with Stable COPD
Table 3. Correlations between rate of change in $\mathrm{FEV}_{1.0}\left(\Delta \mathrm{FEV}_{1.0}\right)$ and parameters measured by FOT $15 \mathrm{~min}, 1$ and $2 \mathrm{~h}$ after inhalation $(n=28)$

\begin{tabular}{|c|c|c|c|c|c|c|}
\hline \multirow[t]{2}{*}{$\Delta \mathrm{FEV}_{1.0}$} & \multicolumn{2}{|c|}{$15 \mathrm{~min}$} & \multicolumn{2}{|l|}{$1 \mathrm{~h}$} & \multicolumn{2}{|l|}{$2 \mathrm{~h}$} \\
\hline & $r$ & $p$ value & $r$ & $p$ value & $r$ & $p$ value \\
\hline$\Delta \mathrm{R} 5$ & -0.39 & $0.04^{*}$ & -0.38 & $0.048^{*}$ & -0.17 & 0.37 \\
\hline$\Delta \mathrm{R} 20$ & -0.48 & $0.009 *$ & -0.42 & $0.02^{*}$ & -0.28 & 0.14 \\
\hline$\Delta$ Fres & -0.25 & 0.13 & -0.5 & $0.007^{*}$ & -0.20 & 0.30 \\
\hline$\triangle \mathrm{ALX}$ & -0.34 & 0.08 & -0.43 & $0.02^{*}$ & -0.16 & 0.42 \\
\hline$\Delta \mathrm{X} 5$ & -0.38 & $0.048^{*}$ & -0.37 & 0.05 & -0.16 & 0.41 \\
\hline
\end{tabular}

* Statistically significant difference.

$\Delta$, rate of changes in R5, R20, Fres, ALX, X5 and FEV 1.0 from before inhalation to $15 \mathrm{~min}, 1$ and $2 \mathrm{~h}$ following inhalation.

For long, COPD has been believed that it represents an irreversible airway obstructive disease. However, current international guidelines state that COPD demonstrates partially reversible airway obstruction [1]. Long-acting bronchodilators are considered a first-line therapy for stable COPD, and a long-acting $\beta_{2}$-agonist (LABA) and a long-acting muscarinic antagonist (LAMA) are frequently prescribed for COPD at present [13]. SABAs are also used for COPD, especially as rescue medication once patients develop dyspnea. On the other hand, use of SABAs as an assist medication for COPD before developing dyspnea is less frequently prescribed. Although many authors have reported that SABA assist use improves symptoms and exercise intolerance in patients with stable 
COPD, it is yet to be determined whether SABA assist use could improve pulmonary function $[2,11,14,15]$. The present study demonstrated that SABA assist use modestly improves pulmonary function in stable COPD. This improvement is likely due to a few factors. First, all subjects in the present study had never used SABAs, and half of the subjects used only LAMA monotherapy. Additionally, the LABAs used in the present study were salmeterol and transdermal tulobuterol, both of which are $\beta_{2}$-partial agonists, and $\beta_{2}$-full-agonists are likely to cause $\beta_{2}$-adrenoceptor tachyphylaxis [16].

Previous reports have demonstrated that COPD patients showed a higher R5-R20 and that bronchodilator therapy significantly decreased it [17]. R5-R20 slightly, but not significantly, decreased after SABA inhalation in the present study. Additionally, R5 values in the present study were lower than previously reported values $[17,18]$. Thus, before SABA inhalation, R5-R20 had already improved because all subjects had used one or more longacting bronchodilators before SABA assist use.

In agreement with another report showing a significant correlation between FOT and spirometry [10], the present study also found significant correlations between them at $15 \mathrm{~min}$ and $1 \mathrm{~h}$ after procaterol use. Although several authors reported the usefulness of FOT parameters in evaluating COPD $[10,19]$, it is not widely used for this purpose. This is probably due to its high cost, low repeatability [20], and high variances caused by the upper airway structure [21]. Thus, FOT cannot be substituted for spirometry in COPD, but spirometry under forced ventilation conditions and FOT under normal breathing conditions may evaluate different physiological parameters.

The present results also suggest that FOT could be a useful clinical examination for patients whose ability to exhale strongly is impaired, for example, elderly persons, patients with unstable cardiac disease, and patients with dyspnea.

In agreement with a previous report [22], the present study also found significant improvements in pulmonary function following SABA assist use compared to baseline. The present study further found that the effects of SABA assist use continued for at least $2 \mathrm{~h}$ after inhalation.

\section{Conclusion}

We have demonstrated that SABA assist use modestly but significantly improves pulmonary function determined by spirometry and respiratory mechanics determined by FOT for patients with stable COPD already treated with a long-acting bronchodilator. Recently, the use of LAMAs, LABAs, and their combination has been shown to play a highly effective central role in the maintenance therapy of COPD $[23,24]$. The present study also indicates the potential role of SABA assist use for stable COPD.

\section{References}

1 Global Initiative for Chronic Obstructive Pulmonary Disease. Global Strategy for the Diagnosis, Management and Prevention of Chronic Obstructive Pulmonary Disease, 2017.

2 Satoh H, Iwashima A, Endo Y, Nakayama H, Hasegawa E, Suzuki E: [Effect of proactive use of inhaled procaterol on dyspnea in daily activities and quality of life in patients with chronic obstructive pulmonary disease]. $\mathrm{Ni}$ hon Kokyuki Gakkai Zasshi 2009;47:772780 .

3 Cooper BG: An update on contraindications for lung function testing. Thorax 2011;66: 714-723.

4 Oostvee E, MacLeod D, Lorino H, Farre R, Hantos Z, Desager Z, Marchal F: The forced oscillation technique in clinical practice: methodology, recommendations and future developments. Eur Respir J 2003;22:1026-1041.

5 Van Noord JA, Clement J, Van de Woestijine KP, Demedts M: Total respiratory resistance and reactance in patients with asthma, chronic bronchitis, and emphysema. Am Rev Respir Dis 1991;143(5 pt 1):922-927.
6 Goldman MD, Carter R, Klein R, Fritz G, Carter B, Pachucki P: Within- and betweenday variability of respiratory impedance, using impulse oscillometry in adolescent asthmatics. Pediatr Pulmonol 2002;34:312-319.

7 Shiota S, Katoh M, Fujii M, Aoki S, Matsuoka R, Fukuchi Y: Predictive equations and the reliability of the impulse oscillatory system in Japanese adult subjects. Respirology 2005; 10: 310-315.

8 Kastelik JA, Aziz I, Ojoo JC, Morice AH: Evaluation of impulse oscillation system: comparison with forced oscillation technique and body plethysmography. Eur Respir J 2001;18: 564-570.

9 Tsuburaii T, Suzuki S, Tsurikisawa N, Mitsui C, Higashi N, Fukutomi Y, Tanimoto H, Sekiya K, Oshikata C, Otomo M, Maeda Y, Taniguchi M, Ikehara K, Akiyama K: Use of forced oscillation technipue to detect airflow limitations in adult Japanese asthmatics. Arerugi 2012;61:184-193.

10 Shibasakii A, Kurosawa H, Tamura G: [Evaluation of airway narrowing by MostGraph and spirometry -examination using a reversibility test]. Arerugi 2013;62:566-573.

11 Mineshita M, Matsuoka S, Miyazawa T: Effects of bronchodilators on regional lung sound distribution in patients with chronic obstructive pulmonary disease. Respiration 2014;87:45-53.

12 Smith HJ, Reinhold P, Goldman MD: CHAPTER5 Forced oscillation technique and impulse oscillometry. Eur Respir Mon 2005;31: 72-105.

13 Barnes PJ: New therapies for chronic obstructive pulmonary disease. Med Princ Pract 2010;19:330-338.

14 Sukisaki T, Senjyu H, Oishi K, Rikitomi N, Ariyoshi K: Single dose of inhaled procaterol has a prolonged effect on exercise performance of patients with COPD. Physiother Theory Pract 2008;24:255-263.

15 Fujimoto K, Yoshiike F, Yasuo M, Kitaguchi Y, Urushihata K, Kubo K, Honda T: Effects of bronchodilators on dynamic hyperinflation following hyperventilation in patients with COPD. Respirology 2007;12:93-99. 
16 Ohishi J, Kurosawa H, Ogawa H, Irokawa T, Hida W, Kohzuki M: Application of impulse oscillometry for within-breath analysis in patients with chronic obstructive pulmonary disease: pilot study. BMJ Open 2011; $1: \mathrm{e} 000184$.

17 Inui N, Matsushima S, Kato S, Yasui H, Kono M, Fujisawa T, Enomoto N, Nakamura Y, Toyoshima M, Suda T: Effects of indacaterol versus tiotropium on respiratory mechanics assessed by the forced oscillation technique in patients with chronic obstructive pulmonary disease. Int J Chron Obstruct Pulmon Dis 2015;10:1139-1146.

18 Yamauchi Y, Kohyama T, Jo T, Nagase T: Dynamic change in respiratory resistance during inspiratory and expiratory phases of tidal breathing in patients with chronic obstructive pulmonary disease. Int J Chron Obstruct Pulmon Dis 2012;7:259-269.

19 da Costa GM, Faria AC, Di Mango AM, Lopes AJ, Lopes de Melo P: Respiratory impedance and response to salbutamol in healthy individuals and patients with COPD. Respiration 2014;88:101-111.

20 Ducharme FM, Davis GM: Measurement of respiratory resistance in the emergency department: feasibility in young children with acute asthma. Chest 1997;111:1519-1525.

21 Bikov A, Pride NB, Goldman MD, Hull JH, Horvath I, Barnes PJ, Usmani OS, Paredi P: Glottal aperture and buccal airflow leaks crit- ically affect forced oscillometry measurements. Chest 2015;148:731-738.

22 Ohbayashi H, Adachi M: Pretreatment with inhaled procaterol improves symptoms of dyspnea and quality of life in patients with severe COPD. Int J Gen Med 2012;5:517-524.

23 Beeh KM, Westerman J, Kirsten AM, et al: The 24-h lung-function profile of once-daily tiotropium and olodaterol fixed-dose combination in chronic obstructive pulmonary disease. Pulm Pharmacol Ther 2015;32:5359.

24 Buhl R, Maltais F, Abrahams R, et al: Tiotropium and olodaterol fixed-dose combination versus mono-components in COPD (GOLD 2-4). Eur Respir J 2015;45:969-979. 